\title{
Low-flow antegrade cerebral perfusion attenuates early renal and intestinal injury during neonatal aortic arch reconstruction
}

\author{
Selma O. Algra, MD, ${ }^{\mathrm{a}}$ Antonius N. J. Schouten, $\mathrm{MD},{ }^{\mathrm{b}}$ Wim van Oeveren, $\mathrm{PhD},{ }^{\mathrm{c}}$ Ingeborg van der \\ Tweel, PhD, ${ }^{\mathrm{d}}$ Paul H. Schoof, MD, ${ }^{\mathrm{a}}$ Nicolaas J. G. Jansen, MD, ${ }^{\mathrm{e}}$ and Felix Haas, MD ${ }^{\mathrm{a}}$
}

Objective: Deep hypothermic circulatory arrest (DHCA) and antegrade cerebral perfusion (ACP) are 2 cardiopulmonary bypass strategies mainly used in aortic arch reconstructions. It has been suggested that during ACP, abdominal organs are better protected than during DHCA owing to partial perfusion via collaterals. We tested this hypothesis using intraoperative near-infrared spectroscopy (NIRS), lactate measurements, and biomarkers for early abdominal injury in neonates undergoing complex aortic arch repair.

Methods: Neonates scheduled for aortic arch reconstruction via median sternotomy between 2009 and 2011 were randomized to either DHCA or ACP. During surgery, regional oxygen saturations of the abdomen were monitored using NIRS. Immediately aafter DHCA or ACP, lactate concentrations from the inferior vena cava were compared with those from the arterial cannula. Postoperatively, biomarkers for early abdominal organ injury were measured in urine.

Results: Twenty-five neonates were analyzed (DHCA, $n=12 ; A C P, n=13$ ). Procedures were performed at $18^{\circ} \mathrm{C}$, and ACP flow was set at 35 to $50 \mathrm{~mL} \cdot \mathrm{kg}^{-1} \cdot \mathrm{min}^{-1}$. Median abdominal NIRS value during DHCA was $31 \%$ (IQR, 28\%-41\%) whereas during ACP it was $56 \%$ (IQR, 34\%-64\%; $P<.01$ between groups). Immediately after DHCA, median lactate from the inferior vena cava was $4.2 \mathrm{mmol} / \mathrm{L}$ (IQR, 3.3-5.3 $\mathrm{mmol} / \mathrm{L}$ ) compared with $3.1 \mathrm{mmol} / \mathrm{L}(\mathrm{IQR}, 2.9-4.4 \mathrm{mmol} / \mathrm{L})$ after ACP $(P=.03)$. Postoperatively, biomarkers for renal and intestinal damage (gluthatione s-transferase and intestinal fatty acid binding protein, respectively) were higher in the DHCA group than for the ACP group $(P=.03, P=.04$, respectively).

Conclusions: These results substantiate earlier suggestions that ACP provides more abdominal organ protection than DHCA in neonates undergoing aortic arch reconstruction. (J Thorac Cardiovasc Surg 2012;144:1323-8)

Earn CME credits at

http://cme.ctsnetjournals.org

Supplemental material is available online.

Deep hypothermic circulatory arrest (DHCA) and antegrade cerebral perfusion (ACP) are 2 cardiopulmonary bypass (CPB) strategies applied in neonatal aortic arch repair. DHCA inherently results in full-body ischemia, whereas in $\mathrm{ACP}$, the brain is selectively perfused at a low flow via the

\footnotetext{
From the Departments of Pediatric Cardiothoracic Surgery, ${ }^{a}$ Anesthesiology, Intensive Care and Emergency Medicine, ${ }^{\mathrm{b}}$ Biostatistics, ${ }^{\mathrm{d}}$ Pediatric Intensive Care, ${ }^{\mathrm{e}}$ University Medical Center Utrecht, Utrecht, The Netherlands; and HaemoScan, ${ }^{c}$ Groningen, The Netherlands.

Disclosures: Authors have nothing to disclose with regard to commercial support.

Received for publication Dec 23, 2011; revisions received Feb 15, 2012; accepted for publication March 12, 2012; available ahead of print April 16, 2012.

Address for reprints: Selma O. Algra, MD, PO Box KG.01.319.0, UMC Utrecht, Lundlaan 6, 3584 EA Utrecht, The Netherlands (E-mail: s.o.algra@umcutrecht.nl). $0022-5223 / \$ 36.00$

Copyright (C) 2012 by The American Association for Thoracic Surgery doi:10.1016/j.jtcvs.2012.03.008
}

innominate artery. Most studies are focused on the neurologic effects of either technique. ${ }^{1,2}$ However, abdominal organ functions also deserve attention inasmuch as postoperative renal function, for instance, is closely related to general postoperative recovery. ${ }^{3}$ Recently, we ${ }^{4}$ have shown that duration of postoperative recovery increases with longer duration of DHCA, whereas duration of ACP has no effect. It is thought that this is due to partial perfusion of the viscera through collaterals during ACP. ${ }^{5-8}$ Others have reported evidence of regional blood flow by abdominal near-infrared spectroscopy (NIRS) or blood pressure measurements in the abdominal or femoral arteries. ${ }^{5,7,8}$ Still, to date, the protective effect of ACP has remained a speculation, inasmuch as abdominal organ injury has not been directly assessed perioperatively.

Various organ-specific biomarkers have proved useful to estimate the extent of abdominal organ injury at an early time point after cardiac surgery or other intensive care settings. ${ }^{9}$ For renal injury, neutrophil gelatinase-associated lipocalin (NGAL) is the most widely reported marker; others include kidney injury molecule-1 (KIM-1), liver fatty acid binding protein (L-FABP), gluthatione s-transferase (GST) and $N$-acetyl- $\beta$-D-glucosaminidase $(\mathrm{NAG}) .{ }^{10-17}$ For intestinal injury, intestinal fatty acid binding protein (I-FABP) is an established early biomarker. ${ }^{18,19}$ 


$$
\begin{aligned}
& \text { Abbreviations and Acronyms } \\
& \mathrm{ACP}=\text { antegrade cerebral perfusion } \\
& \mathrm{CPB}=\text { cardiopulmonary bypass } \\
& \text { DHCA }=\text { deep hypothermic circulatory arrest } \\
& \text { GST = gluthatione s-transferase } \\
& \text { I-FABP }=\text { intestinal fatty acid binding protein } \\
& \mathrm{IQR}=\text { interquartile range } \\
& \text { KIM-1 = kidney injury molecule-1 } \\
& \text { L-FABP }=\text { liver fatty acid binding protein } \\
& \text { NAG }=N \text {-acetyl- } \beta \text {-D-glucosaminidase } \\
& \text { NGAL }=\text { neutrophil gelatinase-associated } \\
& \text { lipocalin } \\
& \text { NIRS = near-infrared spectroscopy }
\end{aligned}
$$

In this study, we assessed the above-named biomarkers of early abdominal injury in neonates undergoing aortic arch reconstructions, before and after surgery. Furthermore, abdominal NIRS and lactate measurements were performed intraoperatively to estimate abdominal perfusion. We hypothesised that ACP would provide more abdominal perfusion and consequently result in less renal and intestinal injury than DHCA.

\section{METHODS \\ Patients and Surgical Procedures}

The current study was performed as part of a prospective randomized controlled trial comparing the neurologic effects of DHCA and ACP (clinicaltrials.gov number NCT01032876). In the subgroup reported here, data on abdominal perfusion were collected; these consisted of intraoperative abdominal NIRS monitoring and lactate measurements and preoperative and postoperative urine analysis of biomarkers for early abdominal injury. The institutional medical ethics committee approved the study and all parents gave informed consent for enrollment. Patients in whom a congenital syndrome was suspected were not eligible for inclusion in the study.

In all patients, surgery was performed through a median sternotomy and standard cannulation techniques with double venous cannulation were applied. In case of interrupted aortic arch, double cannulation of the distal ascending aorta and the pulmonary trunk was performed. CPB was performed using alpha-stat strategy, and patients were cooled for a minimum of 20 minutes to a nasopharyngeal temperature of $18^{\circ} \mathrm{C}$. ACP was performed directly by advancing the arterial cannula into the innominate artery. In the case of a Norwood procedure with a modified BlalockTaussig shunt, the shunt was anastomosed to the innominate artery before aortic arch reconstruction and the shunt was used to deliver ACP. A target flow rate of $25 \%\left(35-50 \mathrm{~mL} \cdot \mathrm{kg}^{-1} \cdot \mathrm{min}^{-1}\right)$ was used with a perfusate temperature of $18^{\circ} \mathrm{C}$ and right radial pressures not exceeding $40 \mathrm{~mm} \mathrm{Hg}$. Depending on the individual anatomic situation, the aortic arch was reconstructed by direct end-to-end or end-to-side anastomosis, reverse subclavian flap and patch plasty, or patch plasty alone. All procedures were performed by a single surgical team.

\section{NIRS Measurements}

Throughout the perioperative period, regional saturations of the frontal cerebrum and the abdomen were estimated using NIRS. For somatic measurement, the electrode (size Pediatric, INVOS, Somanetics, Troy, Mich) was placed longitudinally on the left flank, just caudal of the costal margin. The electrode positioning was verified using ultrasound in the first 10 patients, all showing placement over the left kidney. Mean values of the following 4 periods were calculated: preoperative (minimum of 6 hours of monitoring), deep hypothermic full-flow $\mathrm{CPB}$, during DHCA or ACP, and during the first 30 minutes after reinstitution of normal $\mathrm{CPB}$.

\section{Lactate Measurements}

When aortic arch reconstruction was completed and full-body CPB reinstituted, blood samples were simultaneously drawn from the arterial cannula and the snugged inferior venous cannula within the first minute of reperfusion. After the inferior venous cannula had been temporarily clamped and the first $10 \mathrm{~mL}$ of blood discarded (as this approximates the dead space of the cannula), a sample of $0.5 \mathrm{~mL}$ of blood was drawn from the inferior vena cava for determination of lactate concentration.

\section{Urine Analysis for Biomarkers}

Urine samples were collected preoperatively and postoperatively. Preoperatively, urine was collected before initiation of $\mathrm{CPB}$, and the postoperative time point consisted of urine produced during the second hour after skin closure. NGAL, KIM-1, L-FABP, and I-FABP were measured using enzyme-linked immunosorbent assay. GST (total of $\alpha$ and $\pi$ ) and NAG were measured using colorimetric enzymatic assay. Biomarkers of organ injury were assessed at HaemoScan, Groningen, The Netherlands. Markers were additionally expressed as a ratio of urine production in milliliters per kilogram per hour to correct for dilution of urine. ${ }^{20}$

\section{Statistical Analysis}

Data in text are stated as median (interquartile range [IQR]) or number of patients (percentage of group) unless noted otherwise. Differences in continuous variables between DHCA and ACP groups were compared using the Mann-Whitney $U$ test. SignalBase version 6.76 (University Medical Center Utrecht, The Netherlands) was used for calculation of NIRS values. SPSS version 15.0 (SPSS, Inc, Chicago, Ill) was used for statistical analyses and GraphPad Prism version 5.03 (GraphPad Software, La Jolla, Calif) was used for graphic figures.

\section{RESULTS \\ Patients and Surgical Data}

Specific diagnoses and surgical data are listed in Table 1. Eight neonates underwent univentricular repair, whereas the other 17 underwent biventricular repair. According to the randomization protocol, 12 neonates underwent surgery with DHCA and 13 neonates with ACP.

One patient from the DHCA group died within 30 days postoperatively. Low cardiac output syndrome and renal failure developed, which required peritoneal dialysis at 18 days postoperatively. The patient died 1 week later. None of the other patients had any abdominal complications.

\section{Systemic Saturation and Cerebral NIRS}

The preoperative oxygenation status was similar in both groups. Before the start of $\mathrm{CPB}$, the median systemic saturation in the DHCA group was $97 \%$ (IQR, 93\%-100\%) and for the ACP group this was $98 \%$ (IQR, 95\%-99\%). Regarding preoperative cerebral NIRS values, the DHCA group had a median of $59 \%$ (IQR, $54 \%-67 \%$ ) vs a median of $62 \%$ (IQR, $54 \%-67 \%$ ) for ACP. At deep hypothermic full flow, the DHCA group had a median cerebral NIRS 
TABLE 1. Patient characteristics and operative data

\begin{tabular}{|c|c|c|}
\hline & DHCA $(n=12)$ & $\operatorname{ACP}(\mathbf{n}=13)$ \\
\hline Age at operation (d) & $9(8-11)$ & $9(8-23)$ \\
\hline Weight at operation (kg) & $3.6(3.2-3.8)$ & $3.6(2.5-3.7)$ \\
\hline Gestational age at birth (wk) & $39(38.3-40.0)$ & $39(38.3-40.0)$ \\
\hline \multicolumn{3}{|c|}{ Cardiac diagnoses, biventricular repair $(n=17)$ : } \\
\hline \multicolumn{3}{|l|}{ Hypoplastic aortic arch/CoA, plus: } \\
\hline No intracardiac defects & 0 & 1 \\
\hline VSD & 1 & 3 \\
\hline ASD & 0 & 1 \\
\hline cAVSD & 1 & 0 \\
\hline TGA & 1 & 0 \\
\hline Aortic valve stenosis & 0 & 1 \\
\hline Double-outlet right ventricle & 1 & 1 \\
\hline \multicolumn{3}{|l|}{ Interrupted aortic arch, plus: } \\
\hline VSD, ASD & 0 & 1 \\
\hline $\begin{array}{l}\text { Severe LVOTO (Ross-Konno } \\
\text { procedure) }\end{array}$ & 1 & 0 \\
\hline TGA & 1 & 0 \\
\hline Hypoplastic left heart complex* & 0 & 3 \\
\hline \multicolumn{3}{|l|}{ Univentricular repair $(\mathrm{n}=8)$ : } \\
\hline Hypoplastic left heart syndrome & 4 & 1 \\
\hline Double-inlet left ventricle & 0 & 1 \\
\hline Tricuspid atresia & 2 & 0 \\
\hline \multicolumn{3}{|l|}{ CPB data: } \\
\hline Cooling duration (min) & $35(30-40)$ & $30(29-38)$ \\
\hline $\begin{array}{l}\text { Duration of DHCA or } \\
\text { ACP (min) }\end{array}$ & $33(28-38)$ & $39(32-49)$ \\
\hline Total CPB duration & $167(142-266)$ & $161(129-169)$ \\
\hline $\begin{array}{l}\text { ACP flow rate } \\
\qquad\left(\mathrm{mL} \cdot \mathrm{kg}^{-1} \cdot \mathrm{min}^{-1}\right)\end{array}$ & & $46(41-49)$ \\
\hline $\begin{array}{l}\text { Nasopharyngeal temperature } \\
\text { during DHCA/ACP }\left({ }^{\circ} \mathrm{C}\right)\end{array}$ & $17.3(16.5-18.0)$ & $17.7(17.4-18.3)$ \\
\hline $\begin{array}{l}\text { Rectal temperature during } \\
\text { DHCA/ACP }\left({ }^{\circ} \mathrm{C}\right)\end{array}$ & $20.7(20.0-21.8)$ & $20.7(19.4-21.9)$ \\
\hline
\end{tabular}

Values shown in median (interquartile range) or number of patients. $\mathrm{DHCA}$, Deep hypothermic circulatory arrest; $A C P$, antegrade cerebral perfusion; $C O A$, coarctation of the aortic arch; $V S D$, ventricular septal defect; $A S D$, atrial septal defect; $C A V S D$, complete atrioventricular septal defect; TGA, transposition of the great arteries; LVOTO, left ventricular outflow tract obstruction; $C P B$, cardiopulmonary bypass. *Hypoplastic left heart complex was defined as an underdevelopment of the left heart with significant hypoplasia of the left ventricle and hypoplasia of the aortic and/or mitral valve, ascending aorta and aortic arch, but in the absence of intrinsic valvular stenosis or atresia. ${ }^{21}$

of $80 \%$ (IQR, 70\%-92\%), which was 79\% (IQR, 72\%$85 \%$ ) in the ACP group. During DHCA a median of $51 \%$ was observed (IQR, 49\%-54\%) vs $80 \%$ (IQR, 70\%$88 \%$ ) during ACP. During reperfusion, saturations were $74 \%$ (IQR, $71 \%-79 \%$ ) for the DHCA group and $73 \%$ (IQR, 66\%-78\%) for the ACP group.

\section{Abdominal NIRS}

Abdominal NIRS measurements are depicted in Figure 1. Before surgery, abdominal NIRS values were similar in the 2 groups, with a median of $53 \%$ (IQR, $49 \%-59 \%$ ) in the DHCA group and $56 \%$ (IQR, 48\%-72\%) in the ACP group. At deep hypothermic full-flow CPB, the DHCA

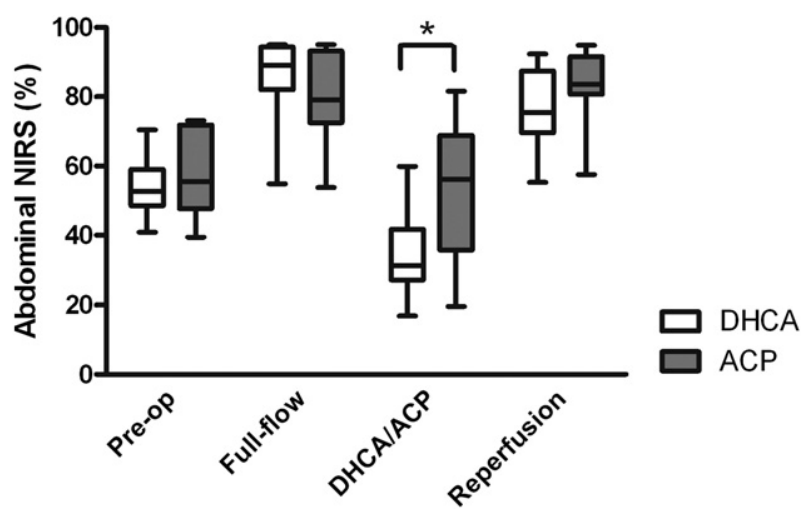

FIGURE 1. Abdominal near-infrared spectroscopy (NIRS) values are lower during deep hypothermic circulatory arrest $(D H C A)$ than during antegrade cerebral perfusion $(A C P)\left({ }^{*} P<.01\right)$. Values are shown in medians and interquartile ranges (boxes) and minimum and maximum values (whiskers). ACP, Antegrade cerebral perfusion; DHCA, deep hypothermic circulatory arrest; NIRS, near-infrared spectroscopy.

group had a median saturation of $89 \%$ (IQR, 79\%-94\%), which was $77 \%$ (IQR, 68\%-92\%) in the ACP group. During DHCA, abdominal NIRS values decreased to a median of $31 \%$ (IQR, $28 \%-41 \%$ ), which was significantly lower than during ACP (median, 56\% [IQR, 36\%-64\%]; $P<.01)$. During the first 30 minutes after reinstitution of normal $\mathrm{CPB}$, the DHCA group had a median value of $74 \%$ (IQR, 67\%-87\%) whereas this was $83 \%$ (IQR, $76 \%-91 \%$ ) in the ACP group.

\section{Lactate Measurements}

Lactate measurements were collected in all but 3 neonates (DHCA, $\mathrm{n}=11$; $\mathrm{ACP}, \mathrm{n}=11$ ) and are shown in Figure 2. Lactate concentrations from the arterial cannula and from the inferior vena cava were compared. Arterial lactate values were similar between DHCA and ACP

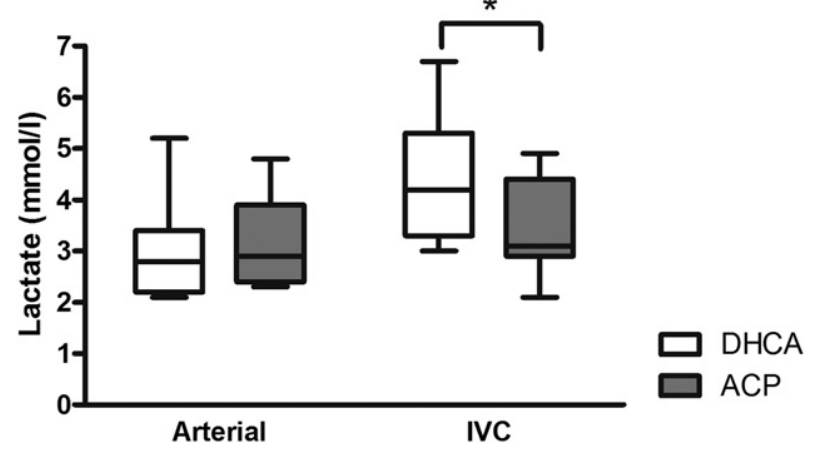

FIGURE 2. Arterial lactate concentrations are similar between deep hypothermic circulatory arrest (DHCA) and antegrade cerebral perfusion $(A C P)$, whereas lactate concentrations from the inferior vena cava $(I V C)$ are significantly higher after DHCA than after ACP $(* P=.03)$. Values are shown in medians and interquartile ranges (boxes) and minimum and maximum values (whiskers). 
TABLE 2. Abdominal biomarker results

\begin{tabular}{|c|c|c|c|c|c|}
\hline & \multicolumn{2}{|c|}{ DHCA } & \multicolumn{2}{|c|}{$\mathbf{A C P}$} & \multirow{2}{*}{$\begin{array}{l}P \text { value postop } \\
\text { (DHCA vs ACP) }\end{array}$} \\
\hline & Preop $(\mathbf{n}=9)$ & Postop $(n=11)$ & $\operatorname{Preop}(\mathbf{n}=10)$ & Postop $(n=12)$ & \\
\hline \multicolumn{6}{|l|}{ Absolute urinary concentrations } \\
\hline \multicolumn{6}{|l|}{ Renal injury } \\
\hline NGAL & $89(4.6-149)$ & $185(92-235)$ & $27(9.2-60)$ & $47(24-117)$ & .07 \\
\hline GST & $5.2(2.4-6.0)$ & $7.2(5.3-7.9)$ & $5.4(2.0-6.7)$ & $3.8(2.2-6.1)$ & .03 \\
\hline L-FABP & $128(55-426)$ & $262(43-421)$ & $83(34-312)$ & $132(22-607)$ & .61 \\
\hline NAG & $8.6(0.9-18)$ & $39(9.7-67)$ & $8.1(2.7-20)$ & $24(6.2-53)$ & .50 \\
\hline KIM-1 & $2.7(0.7-6.3)$ & $1.5(0.6-10.0)$ & $1.1(0.4-2.3)$ & $0.6(0.2-2.8)$ & .14 \\
\hline \multicolumn{6}{|l|}{ Intestinal injury } \\
\hline I-FABP & $11(6.7-90)$ & $82(30-180)$ & $15(7.9-38)$ & $11(0.0-101)$ & .04 \\
\hline \multicolumn{6}{|l|}{ Results corrected for urine output } \\
\hline \multicolumn{6}{|l|}{ Renal injury } \\
\hline NGAL & $19(1.2-78)$ & $119(84-136)$ & $11(5.3-22)$ & $14(5.8-53)$ & $<.01$ \\
\hline GST & $1.2(0.5-3.7)$ & $4.7(2.8-5.9)$ & $0.9(0.3-2.4)$ & $1.4(0.3-2.5)$ & .02 \\
\hline L-FABP & $83(13-280)$ & $271(39-541)$ & $37(5.6-101)$ & $19(9.6-88)$ & .03 \\
\hline NAG & $3.8(0.1-7.6)$ & $26(4.4-61)$ & $2.3(1.1-5.6)$ & $5.1(1.5-26)$ & .11 \\
\hline KIM-1 & $0.5(0.1-4.3)$ & $1.4(0.2-7.8)$ & $0.4(0.2-1.0)$ & $0.4(0.03-1.0)$ & .05 \\
\hline \multicolumn{6}{|l|}{ Intestinal injury } \\
\hline I-FABP & $6.6(1.5-65)$ & $19(59-134)$ & $3.9(0.00-13)$ & $1.5(0.00-39)$ & .01 \\
\hline Urine output $\left(\mathrm{mL} \cdot \mathrm{kg}^{-1} \cdot \mathrm{h}^{-1}\right)$ & $4.2(2.4-6.8)$ & $1.5(0.8-3.1)$ & $4.0(2.4-5.8)$ & $2.8(1.4-6.3)$ & .10 \\
\hline
\end{tabular}

Values are shown in median (interquartile range). $D H C A$, Deep hypothermic circulatory arrest; $A C P$, antegrade cerebral perfusion; $N G A L$, neutrophil gelatinase-associated lipocalin (ng/mL); GST, gluthatione s-transferase (U/mL); L-FABP, liver fatty acid binding protein (ng/mL); $N A G, N$-acetyl- $\beta$-D-glucosaminidase (mU/mL); KIM- 1, kidney injury molecule-1 (ng/mL); I-FABP, intestinal fatty acid binding protein $(\mathrm{ng} / \mathrm{mL})$.

(median DHCA, $2.8 \mathrm{mmol} / \mathrm{L}$ [IQR, 2.2-3.4 mmol/L]; median, ACP, $2.9 \mathrm{mmol} / \mathrm{L}$ [IQR, 2.4-3.9 mmol/L]). After DHCA, lactate from the inferior vena cava had a median of $4.2 \mathrm{mmol} / \mathrm{L}$ (IQR, 3.3-5.3 $\mathrm{mmol} / \mathrm{L}$ ), which was significantly higher than the caval lactate in the ACP group (median, $3.1 \mathrm{mmol} / \mathrm{L}$ [IQR, 2.9-4.4 mmol/L]; $P=.03$ ).

\footnotetext{
Abdominal Biomarkers

Biomarkers of renal and intestinal injury were measured preoperatively in 19 neonates (DHCA, $\mathrm{n}=9 ; \mathrm{ACP}, \mathrm{n}=10$ ) and postoperatively in 23 neonates (DHCA, $\mathrm{n}=11$; ACP, $\mathrm{n}=12$ ). Results are listed in Table 2 . The absolute concentrations of the renal marker GST and intestinal marker I-FABP were significantly higher postoperatively in the DHCA group compared with the ACP group $(P=.03$ and $P=.04$, respectively). Regarding the other markers of renal injury (NGAL, L-FABP, NAG, and KIM-1), the difference of postoperative values between DHCA and ACP did not reach statistical significance $(P=.07, P=.61, P=.50$, and $P=.14$, respectively). When correcting for urine output at the time of sampling, all markers except NAG and KIM-1 were significantly higher postoperatively in the DHCA group than the ACP group (NGAL, $P<.01$; GST, $P=.02$; L-FABP, $P=.03$; NAG, $P=.11$; KIM- $1, P=.05$; and I-FABP, $P=.01)$. The median postoperative urine output itself was $1.5 \mathrm{~mL} \cdot \mathrm{kg}^{-1} \cdot \mathrm{h}^{-1}$ in the DHCA group vs $3.0 \mathrm{~mL} \cdot \mathrm{kg}^{-1}$. $\mathrm{h}^{-1}$ in the ACP group $(P=.10)$. Stratified by univentricular and biventricular repair, the median and ranges for the various biomarkers are listed in Table E1.
}

Serum creatinine and blood urea nitrogen levels were available for a limited number of patients preoperatively (DHCA, $\mathrm{n}=12 ; \mathrm{ACP}, \mathrm{n}=12$ ) and postoperatively (DHCA, $\mathrm{n}=7$; ACP, $\mathrm{n}=6$ ). For blood urea nitrogen, a significant difference between postoperative levels was detected $(P=.03)$ whereas for creatinine this was $P=.05$. Results are listed in Table E2.

\section{DISCUSSION}

The results of the current study substantiate that in neonates undergoing complex aortic arch repair, abdominal organs are better protected by low-flow ACP than by DHCA. During DHCA, abdominal NIRS values were lower and lactate concentrations higher than during ACP, likely resulting in the increased concentrations of renal and intestinal organ damage markers after surgery.

The current findings confirm earlier suggestions in literature. Pigula and associates ${ }^{8}$ were the first to measure evidence of flow in the abdominal aorta during ACP. Since then, others have assessed abdominal NIRS trends during $\mathrm{ACP}$ and have found that NIRS values rise with increasing ACP flow rate. ${ }^{5,7,22}$ Recently, we ${ }^{4}$ have added to the literature that DHCA duration during aortic arch reconstruction is linearly related to the duration of postoperative recovery, whereas ACP is not. Taken together, these findings strongly point toward the phenomenon of abdominal perfusion during ACP.

We intended to assess markers of organ injury as close to the insult as possible. This explains the choice for the 
biomarkers used in this study, instead of the more widely known markers such as creatinine and urea for renal function. The latter markers are known to measure organ function and are generally raised 1 to 3 days after surgery, whereas the current biomarkers in this study are able to detect early organ injury, making factors such as low cardiac output less likely to obscure results. ${ }^{9}$ Renal injury was assessed by 5 different biomarkers. Of these, NGAL has generally been researched most extensively. Recently, 2 large studies validated the marker in the pediatric cardiac surgery population and observed that acute kidney injury could be detected by NGAL as early as 2 hours after surgery with mean values of 300 to $500 \mathrm{ng} / \mathrm{mL} .^{10,11}$ Krawczeski and colleagues $^{11}$ specifically calculated a cutoff point for the neonatal population at $185 \mathrm{ng} / \mathrm{mL}$. When this is applied to our cohort, after surgery, 5 of the 12 in the DHCA group would find themselves above this threshold vs 2 of 13 in the ACP group. When comparing the concentrations of the current group of neonates with those reported for all 5 renal biomarkers used in this study, some of the organ injury markers are already elevated in the patients preoperatively, likely reflecting the compromised cardiac situation. Postoperatively, the values in the DHCA group indicate that substantial renal injury has occurred, whereas this is much less the case after ACP.

Previously published articles concerning renal biomarkers have mostly reported absolute urinary concentrations in their studies. ${ }^{10-17}$ However, correction to the urine production at the time of sampling has recently been stated to be the most reliable way of assessing renal injury. ${ }^{20}$ Inasmuch as differences between DHCA and ACP became especially apparent in the analysis corrected for urine production, this confirms that DHCA results in more renal injury than ACP.

Intestinal injury was estimated using I-FABP, which has been used in both adults and neonates to determine intestinal ischemia. ${ }^{18,19}$ Compared with these reports, the preoperative values are acceptable whereas the postoperative values after DHCA are among the highest reported, indicating that the intestinal injury is substantial after DHCA. In contrast, after $\mathrm{ACP}$, the values seem to be in the normal range.

Abdominal NIRS values during ACP showed a large variation between patients. This is likely due to both a varying degree of collaterals and a varying duration of ACP. Consequently, this does indicate that abdominal perfusion cannot be guaranteed in the individual patient during ACP, but at a group level, ACP does seem to provide protection from ischemic renal and intestinal injury. The lactate measurements support this notion, inasmuch as these were generally increased in the DHCA group, whereas they remained unchanged in the ACP group. Neonates with aortic arch obstructions are probably ideal candidates for the advantageous effects of ACP, inasmuch as their anatomy will have stimulated the growth of collaterals traveling from the aortic arch and the innominate arteries, via the mammary and epigastric arteries, to the abdominal viscera. ${ }^{23-25}$

This study has important limitations that deserve consideration. First, apart from NGAL, the various biomarkers have not been validated in this specific population and the limited sample size in the current study prevents this. However, as these markers are known to show early injury, we chose to primarily assess these instead of the more traditional markers. These markers are currently as close to the injury as one can get. Ultimately, histologic assays (in animal models) can only confirm specific organ injury; however, a significant limitation to the use of animals is the different collateralization pattern. The second important limitation is the small sample size, which will have resulted in a lower power to detect statistical differences between the DHCA and ACP groups. Furthermore, despite the randomization for DHCA and ACP, the proportion of univentricular and biventricular patients between the 2 groups is unbalanced. To minimize the impact of a low cardiac output state on biomarker results, we collected urine samples very shortly after surgery.

In conclusion, the results presented here show that during neonatal aortic arch reconstruction, ACP provides more abdominal perfusion than does DHCA. As a consequence, this likely has a protective effect on abdominal organs. The current results explain findings in previous studies showing an adverse effect of DHCA, but not ACP, on early postoperative recovery.

We thank F. C. M. Evens and F. de Roo (surgical team) and the perfusionists at Heartbeat (Utrecht, The Netherlands) for assistance in sample collection during surgery.

\section{References}

1. Goldberg CS, Bove EL, Devaney EJ, Mollen E, Schwartz E, Tindall S, et al. A randomized clinical trial of regional cerebral perfusion versus deep hypothermic circulatory arrest: outcomes for infants with functional single ventricle. J Thorac Cardiovasc Surg. 2007;133:880-7.

2. Visconti KJ, Rimmer D, Gauvreau K, del Nido P, Mayer JE Jr, Hagino I, et al. Regional low-flow perfusion versus circulatory arrest in neonates: one-year neurodevelopmental outcome. Ann Thorac Surg. 2006;82:2207-11.

3. Brown KL, Ridout DA, Goldman AP, Hoskote A, Penny DJ. Risk factors for long intensive care unit stay after cardiopulmonary bypass in children. Crit Care Med. 2003;31:28-33.

4. Algra SO, Kornmann VN, van der Tweel I, Schouten AN, Jansen NJ, Haas F. Increasing duration of circulatory arrest, but not antegrade cerebral perfusion, prolongs postoperative recovery after neonatal cardiac surgery. J Thorac Cardiovasc Surg. 2012;143:375-82. Epub 2011 Sep 8.

5. Andropoulos DB, Stayer SA, McKenzie ED, Fraser CD Jr. Novel cerebral physiologic monitoring to guide low-flow cerebral perfusion during neonatal aortic arch reconstruction. J Thorac Cardiovasc Surg. 2003;125:491-9.

6. Ly M, Roubertie F, Belli E, Grollmuss O, Bui MT, Roussin R, et al. Continuous cerebral perfusion for aortic arch repair: hypothermia versus normothermia. Ann Thorac Surg. 2011;92:942-8.

7. Miyaji K, Miyamoto T, Kohira S, Itatani K, Tomoyasu T, Inoue N, et al. Regional high-flow cerebral perfusion improves both cerebral and somatic tissue oxygenation in aortic arch repair. Ann Thorac Surg. 2010;90:593-9.

8. Pigula FA, Gandhi SK, Siewers RD, Davis PJ, Webber SA, Nemoto EM. Regional low-flow perfusion provides somatic circulatory support during neonatal aortic arch surgery. Ann Thorac Surg. 2001;72:401-6. 
9. Devarajan P. Biomarkers for the early detection of acute kidney injury. Curr Opin Pediatr. 2011;23:194-200.

10. Bennett M, Dent CL, Ma Q, Dastrala S, Grenier F, Workman R, et al. Urine NGAL predicts severity of acute kidney injury after cardiac surgery: a prospective study. Clin J Am Soc Nephrol. 2008;3:665-73.

11. Krawczeski CD, Woo JG, Wang Y, Bennett MR, Ma Q, Devarajan P. Neutrophil gelatinase-associated lipocalin concentrations predict development of acute kidney injury in neonates and children after cardiopulmonary bypass. $J$ Pediatr. 2011;158:1009-15.

12. Westhuyzen J, Endre ZH, Reece G, Reith DM, Saltissi D, Morgan TJ. Measurement of tubular enzymuria facilitates early detection of acute renal impairment in the intensive care unit. Nephrol Dial Transplant. 2003;18:543-51.

13. Portilla D, Dent C, Sugaya T, Nagothu KK, Kundi I, Moore P, et al. Liver fatty acid-binding protein as a biomarker of acute kidney injury after cardiac surgery. Kidney Int. 2008;73:465-72.

14. Askenazi DJ, Koralkar R, Levitan EB, Goldstein SL, Devarajan P, Khandrika $\mathrm{S}$, et al. Baseline values of candidate urine acute kidney injury (AKI) biomarkers vary by gestational age in premature infants. Pediatr Res. 2011;70:302-6.

15. Du Y, Zappitelli M, Mian A, Bennett M, Ma Q, Devarajan P, et al. Urinary biomarkers to detect acute kidney injury in the pediatric emergency center. Pediatr Nephrol. 2011;26:267-74.

16. Liang XL, Liu SX, Chen YH, Yan LJ, Li H, Xuan HJ, et al. Combination of urinary kidney injury molecule- 1 and interleukin- 18 as early biomarker for the diagnosis and progressive assessment of acute kidney injury following cardiopulmonary bypass surgery: a prospective nested case-control study. Biomarkers. 2010;15:332-9.
17. Liangos O, Tighiouart H, Perianayagam MC, Kolyada A, Han WK, Wald R, et al. Comparative analysis of urinary biomarkers for early detection of acute kidney injury following cardiopulmonary bypass. Biomarkers. 2009;14:423-31.

18. Thuijls G, van Wijck K, Grootjans J, Derikx JP, van Bijnen AA, Heineman E, et al. Early diagnosis of intestinal ischemia using urinary and plasma fatty acid binding proteins. Ann Surg. 2011;253:303-8.

19. Derikx JP, Evennett NJ, Degraeuwe PL, Mulder TL, van Bijnen AA, van Heurn LW, et al. Urine based detection of intestinal mucosal cell damage in neonates with suspected necrotising enterocolitis. Gut. 2007;56:1473-5.

20. Waikar SS, Sabbisetti VS, Bonventre JV. Normalization of urinary biomarkers to creatinine during changes in glomerular filtration rate. Kidney Int. 2010;78:486-94.

21. Tchervenkov CI, Jacobs JP, Weinberg PM, Aiello VD, Beland MJ, Colan SD, et al. The nomenclature, definition and classification of hypoplastic left heart syndrome. Cardiol Young. 2006;16:339-68.

22. Hoffman GM, Stuth EA, Jaquiss RD, Vanderwal PL, Staudt SR, Troshynski TJ, et al. Changes in cerebral and somatic oxygenation during stage 1 palliation of hypoplastic left heart syndrome using continuous regional cerebral perfusion. $J$ Thorac Cardiovasc Surg. 2004;127:223-33.

23. Freund MW, Vollebregt AM, Krings G, Vonken EP, Agostoni P, Meijboom FJ. Native atretic coarctation of the aorta in a 37-year-old hypertensive woman, treated with a low-profile covered stent. Neth Heart J. 2011 May 21 [Epub ahead of print.].

24. Mathew R, Simon G, Joseph M. Collateral circulation in coarctation of aorta in infancy and childhood. Arch Dis Child. 1972;47:950-3.

25. Yurdakul M, Tola M, Ozdemir E, Bayazit M, Cumhur T. Internal thoracic arteryinferior epigastric artery as a collateral pathway in aortoiliac occlusive disease. J Vasc Surg. 2006;43:707-13. 
TABLE E1. Abdominal biomarkers: Univentricular and biventricular repairs

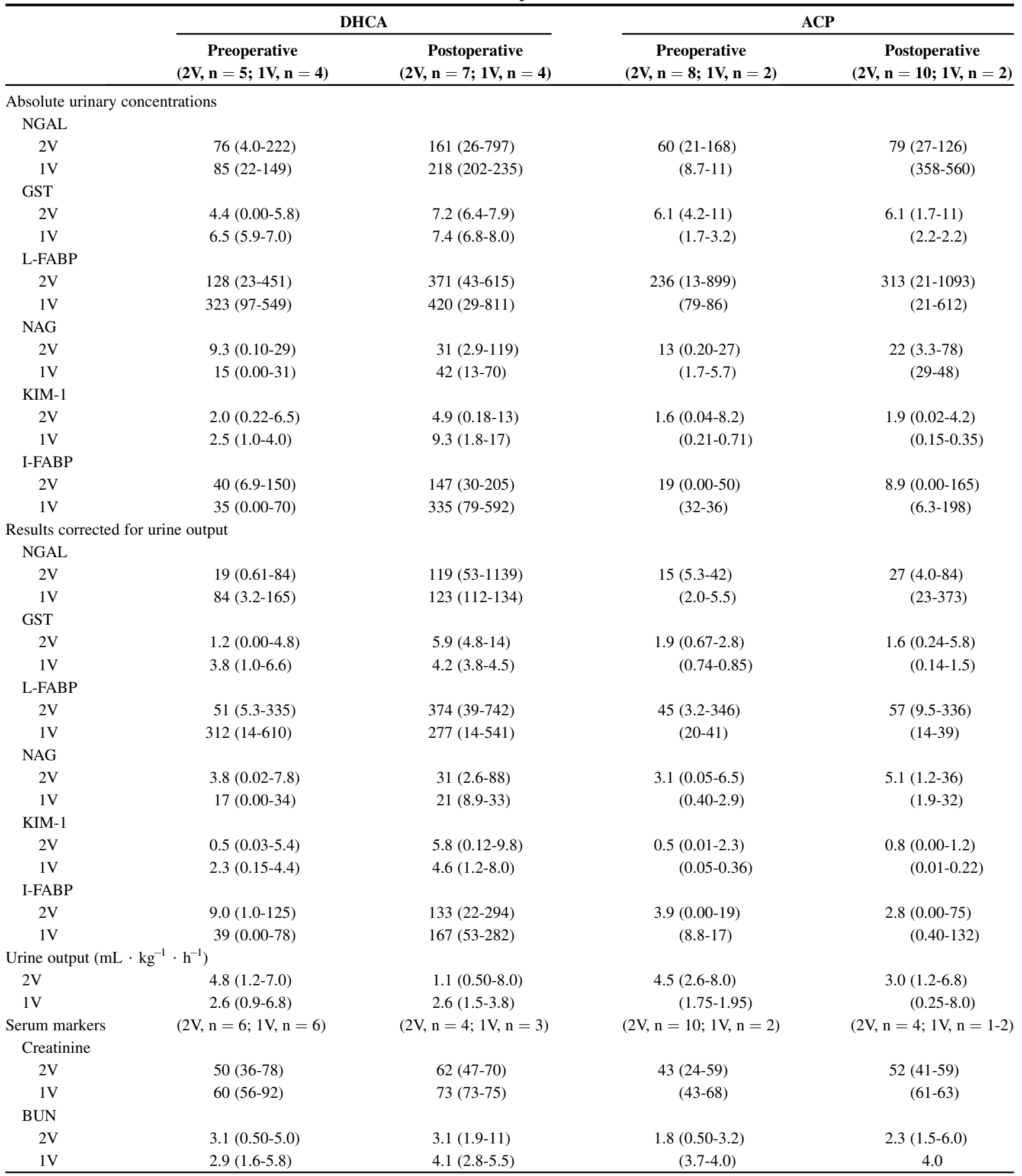

$I V$, Univentricular; $2 V$, biventricular; $D H C A$, deep hypothermic circulatory arrest; $A C P$, antegrade cerebral perfusion; $N G A L$, neutrophil gelatinase-associated lipocalin (ng/ $\mathrm{mL}) ; G S T$, gluthatione s-transferase $(\mathrm{U} / \mathrm{mL}) ; L-F A B P$, liver fatty acid binding protein $(\mathrm{ng} / \mathrm{mL}) ; N A G, N$-acetyl- $\beta$-D-glucosaminidase $(\mathrm{mU} / \mathrm{mL}) ; K I M-1$, kidney injury molecule-1 (ng/mL); I-FABP, intestinal fatty acid binding protein $(\mathrm{ng} / \mathrm{mL}) ; B U N$, blood urea nitrogen. 
TABLE E2. Serum markers of renal function

\begin{tabular}{|c|c|c|c|c|c|}
\hline & \multicolumn{2}{|c|}{ DHCA } & \multicolumn{2}{|c|}{$\mathrm{ACP}$} & \multirow{2}{*}{$\begin{array}{c}P \text { value } \\
\text { postoperative } \\
(\text { DHCA vs ACP) }\end{array}$} \\
\hline & $\begin{array}{l}\text { Preoperative } \\
\quad(n=12)\end{array}$ & $\begin{array}{c}\text { Postoperative } \\
(\mathbf{n}=7)\end{array}$ & $\begin{array}{l}\text { Preoperative } \\
(n=12)\end{array}$ & $\begin{array}{c}\text { Postoperative } \\
(\mathbf{n}=\mathbf{6})\end{array}$ & \\
\hline Creatinine & $58(46-69)$ & $70(54-73)$ & $43(39-55)$ & $55(45-60)$ & .05 \\
\hline BUN & $2.9(1.4-4.2)$ & $3.6(2.9-5.2)$ & $2.0(1.4-3.1)$ & $2.3(1.4-3.1)$ & .03 \\
\hline
\end{tabular}

$D H C A$, Deep hypothermic circulatory arrest; $A C P$, antegrade cerebral perfusion; $B U N$, blood urea nitrogen. 